\title{
Does knowing about the long-term health effects of alcohol matter? Evidence from a university sample in Lebanon
}

\author{
Nicole Khauli, ${ }^{1}$ Lilian A. Ghandour, ${ }^{2}$ Sirine Anouti, ${ }^{2}$ Rima A. Afifi, ${ }^{3,4}$ Rima Nakkash, ${ }^{3}$ Ali Chalak, ${ }^{5}$ Nasser Yassin ${ }^{6}$ and Silvia S. Martins ${ }^{1}$
}

${ }^{1}$ Department of Epidemiology, Columbia University Mailman School of Public Health, New York, United States of America. ${ }^{2}$ Department of Epidemiology and Population Health, Faculty of Health Sciences, American University of Beirut, Beirut, Lebanon (Correspondence to: Lilian Ghandour: lgo1@aub.edu. lb). ${ }^{3}$ Department of Health Promotion and Community Health, Faculty of Health Sciences, American University of Beirut, Beirut, Lebanon. ${ }^{4}$ Department of Community and Behavioral Health, College of Public Health, University of Iowa, Iowa City, United States of America. ${ }^{5}$ Department of Agriculture, Faculty of Agricultural and Food Sciences, American University of Beirut, Beirut, Lebanon. ${ }^{6}$ Department of Health Management and Policy, Faculty of Health Sciences, American University of Beirut, Beirut, Lebanon.

\begin{abstract}
Background: Research linking awareness of health effects of alcohol and harmful alcohol drinking status is limited. Aims: To investigate the association between awareness of long-term alcohol effects and alcohol use disorders.

Methods: University students aged $18-25$ years $(n=1155)$ completed a self-filled survey. Participants were asked if they knew that alcohol causes: (1) problems in the liver; (2) cancers of the mouth, throat, oesophagus and breast; (3) damage to the heart; and (4) weakening of the immune system. Multinomial regression analyses were conducted to assess the association between awareness of long-term alcohol effects and alcohol drinking status, including Diagnostic and Statistical Manual of Mental Disorders, 5th Edition (DSM-5) alcohol use disorders.

Results: One third (32.8\%) were past-year drinkers and 18\% screened positive for DSM-5 alcohol use disorders. Compared to past-year drinkers with no alcohol use disorders, non-past-year ever drinkers were twice as likely to know about the link between alcohol and cancers of the mouth, throat, oesophagus and breast. Past-year drinkers with an alcohol use disorders were less likely to know about this association. Non-past-year ever drinkers (vs past-year drinkers with no alcohol use disorders) were also 2.6 times more likely to know the alcohol liver risks.

Conclusions: There is a strong inverse relationship between awareness of the effects of alcohol and harmful consumption among young people, providing preliminary support for the protective nature of knowledge on alcohol drinking status. Efforts to increase public awareness of the long-term health effects of alcohol may be useful in reducing alcohol-related harm.

Keywords: alcohol consumption, alcohol use disorders, college students, cancer, health awareness

Citation: Khauli N; Ghandour LA; Anouti S; Afifi RA; Nakkash R; Chalak A; et al. Does knowing about the long-term health effects of alcohol matter? Evidence from a university sample in Lebanon. East Mediterr Health J. 2021;27(4):336-343. https://doi.org/10.26719/emhj.20.113

Received: 28/07/19; accepted: 28/04/20

Copyright (C) World Health Organization (WHO) 2021. Open Access. Some rights reserved. This work is available under the CC BY-NC-SA 3.0 IGO license (https://creativecommons.org/licenses/by-nc-sa/3.o/igo)
\end{abstract}

\section{Introduction}

Globally, alcohol consumption is one of the leading risk factors for death and disability (1). Drinking habits that are formed in young adulthood - a period marked by increased susceptibility to development of addiction and alcohol dependence (2) - are likely to be maintained in adulthood (3). Research data from the United States of America show that alcohol use disorders (AUDs) are most prevalent in young adults aged 18-29 years (4). A meta-analysis has shown that, compared to the general population, people with a diagnosed AUD are 10 times more likely to die from liver cirrhosis as well as mental disorders, which encompass both alcoholism and other mental comorbidity (5).

Despite the overwhelming evidence of the detrimental effects of alcohol on health, public knowledge and awareness of the harmful consequences of alcohol consumption remain low, with around half of adults only aware of some link between alcohol and negative health consequences $(6-8)$. This is especially true for long- term health effects like cancer (9). A recent study found that most Australian adults associated alcohol use with liver cirrhosis and cancer, but only a small proportion associated it with other long-term health effects like heart disease, stroke and cancers of the mouth, throat and breast (10). Studies linking awareness of risk with corresponding alcohol consumption have been limited, with mixed results. One cross-sectional study from England in adults aged $\geq 18$ years showed that level of awareness of cancer risk of alcohol was not associated with their risk of AUD, as screened by the Alcohol Use Disorders Test short form (AUDIT-C) (7). Specifically, identifying as no- or low-risk (score $<5$ ) versus high-risk (score $\geq 5$ ) drinkers was not related to cancer awareness, as measured by responses to unprompted questions about health effects of alcohol, as well as identification of cancer types from a list of alcohol-related cancers. However, a study from Australia investigated participant knowledge of various risk factors for cancer, including alcohol use, and found that identification of alcohol use as a moderate/large risk factor for cancer was associated 
with lower-risk drinking, as measured by the AUDIT-C (11). One longitudinal study found that the development of risk perceptions, measured by asking participants how dangerous the consumption of a substance is to the general population, seemed to influence future use of alcohol, tobacco and cannabis in young people (12). This reinforces an earlier study showing that alcohol knowledge, including perceived prevalence and health information related to alcohol consumption, had a negative effect on later alcohol consumption in adolescents (13). Thus, while some studies point to a significant association between knowledge of the health consequences of alcohol and drinking patterns (11-13), others have found no such effect (7). These differences are not because the studies on public awareness of the harmful effects of alcohol used different forms of measurement, with most of the studies using only one or two questions to measure this knowledge $(6,14)$.

Besides the mixed results, and the measurement issue, the overwhelming evidence on this topic remains predominantly drawn from western countries, focusing mainly on adults $(6-9,11)$. Research data from other parts of the world, particularly Arab countries, remain limited (15). Studies from Lebanon have highlighted the common and increasing practice of alcohol consumption among adolescents (16). One study reported a $40 \%$ increase in the percentage of past-30-day alcohol drinkers among middle-school students between 2005 and 2011, with $>80 \%$ of the lifetime drinkers having tried their first alcoholic drink before the age of 14 years (16). In Lebanon, alcohol is widely accessible, particularly around schools and universities (17), and alcohol policies remain absent or poorly enforced (15). Studies investigating risk and protective factors of alcohol consumption in young people in Lebanon date back to 1999 (18). More recent discussions with young people have highlighted that alcohol availability and accessibility, social learning from peers and family, and social control have a critical impact on alcohol consumption (19).

The present study extends current research on alcohol consumption in college students in general, and Lebanon in particular. By using a robust measure of health awareness, we investigated the association between awareness of long-term alcohol effects and alcohol drinking status, as defined by the Diagnostic and Statistical Manual of mental disorders, 5 th edition (DSM5) (20). Consistent with research on knowledge of alcohol effects and related outcomes (13), we hypothesized that we would observe a negative association between awareness of long-term alcohol effects and AUDs.

\section{Methods}

\section{Study design and participants}

A sample of 1155 university students aged 18-25 years was conveniently recruited from 6 public and private universities in Lebanon between April and May 2016. The study followed a cross-sectional survey design. Universities were selected to ensure inclusion of large academic institutions, located in various areas of the country, with varying educational approaches based on 3 languages of instruction (Arabic, French or English), and distinct socioeconomic compositions based on yearly tuition fees. Students were approached by trained field workers on and off campus, including surrounding outlets frequented by students. The study had a good response rate (83.1\%) and ethical approval was obtained from the American University of Beirut Institutional Review Board. The data are part of a larger research initiative aimed at gathering evidence to inform a national alcohol policy for Lebanon.

\section{Survey}

Students completed a self-filled survey that was initially developed in English, translated into Arabic, and then back translated into English. Students chose to complete the survey in their language of preference. The survey consisted of several questions that measured participants' alcohol consumption, awareness of long-term alcohol effects, as well policy-relevant covariates on perceived alcohol availability, affordability and advertising. Participants who gave oral informed consent completed the survey via pencil and paper.

\section{Measures}

\section{Awareness of long-term alcohol effects (explanatory variable)}

Participating students were asked if they, based on what they know or believe, thought that drinking too much (whether on a single occasion or over time) causes: 1- problems in the liver (fatty liver, alcoholic hepatitis, and cirrhosis); 2- cancers of the mouth, throat, oesophagus and breast; 3 - damage to the heart causing irregular heartbeats, stroke or hypertension; and 4- weakening of the immune system. Responses were dichotomous (yes: correct, and no: incorrect); a "don't know" response was treated as an incorrect answer given that study findings were intended to inform awareness-raising approaches.

\section{Alcohol drinking status (outcome variable)}

Past-year drinkers (students who had consumed at least 1 drink in the preceding year) were asked a set of questions to screen for DSM-5 defined AUD (20). By answering these questions, they were given an AUD score ranging from 0 to 11, and presence of at least 2 of these symptoms indicated an AUD. Our outcome variable was alcohol drinking status, a categorical measure including: $1-$ abstainers (never tried alcohol); 2- non-past-year drinkers (tried alcohol but did not drink in the past year); 3- pastyear drinkers with no AUD (drank in the past year but did not meet DSM-5 criteria for an AUD); and 4- past-year drinkers with an AUD (drank in the past year and met DSM-5 criteria for an AUD).

\section{Demographic characteristics and other covariates (potential confounders)}

Demographics assessed included sex, age (older or younger than 21 years), and level of education (bachelor's degree or higher). Demographics and other covariates were controlled for in our adjusted models. Given the well-established literature on smoking and its associa- 
tion with alcohol consumption $(21,22)$ and AUDs among young people (23), tobacco use was considered. Two variables were combined to measure tobacco use: cigarette use, defined as having smoked $\geq 1$ cigarettes per day in the last 12 months (yes, no); and waterpipe use, defined as having smoked 1 waterpipe per week in the last 12 months (yes, no). Waterpipe use is a popular alternative tobacco product among young people in the region (24-26). Interpersonal factors, like peer/friend approval of drinking, can also influence substance use in adolescents and young adults $(27,28)$. We included the variable perceived friend approval, which was measured by asking to what extent respondents' close friends approved or disapproved of them drinking alcohol. Additionally, exposure to alcohol advertising within the 12 months preceding the survey was recorded, specifically "don't drink and drive" messages on television, radio, social media, billboards, or text messages. Given that the sample consisted of students attending 7 campuses and representing 6 private and public universities in Lebanon, university affiliation was adjusted for in statistical analyses.

\section{Statistical analysis}

Statistical analysis was conducted using Stata version 13.0. First, descriptive statistics of the sample were generated for all variables, followed by bivariate analyses of the awareness measures with alcohol drinking status and relevant covariates using Pearson's $c^{2}$ statistics and their associated $\mathrm{P}$ value. Aligned with the directionality of associations from previous research (13), we considered the outcome of this study to be alcohol drinking status and the main explanatory variable to be awareness of effects of alcohol. Multinomial logit analysis was conducted to examine the direction and magnitude of the crude unadjusted associations of awareness of alcohol drinking status (Model 1), and adjusted associations controlling for potential confounders (Models 2 and 3). Model 2 adjusted for age, sex and university affiliation only. Model 3 adjusted for age, sex, university affiliation, level of education, past-year tobacco use, perceived friend approval, and exposure to alcohol advertising. Past-year drinkers without an AUD were assigned as the reference category in all models. All models accounted for clustering at the level of the university to generate more robust standard error estimates. Adjusted and unadjusted odds ratios with $95 \%$ confidence intervals (CIs) of awareness of long-term alcohol effects on the outcome of alcohol drinking status are presented in Table 2 , but only adjusted estimates were interpreted.

\begin{tabular}{|c|c|c|c|c|c|c|}
\hline \multirow[t]{3}{*}{ Characteristic } & \multirow[t]{2}{*}{ Total } & \multicolumn{4}{|c|}{ Drinker type } & \multirow{3}{*}{$\chi^{2}$ P value } \\
\hline & & Abstainers & \multirow{2}{*}{$\begin{array}{c}\text { non-PY } \\
\text { drinkers } \\
\%(n)\end{array}$} & \multirow{2}{*}{$\begin{array}{c}\text { PY no AUD } \\
\%(n)\end{array}$} & \multirow{2}{*}{$\begin{array}{c}\text { PY AUD } \\
\%(n)\end{array}$} & \\
\hline & $\%(n)$ & $\%(n)$ & & & & \\
\hline \multicolumn{7}{|l|}{ Age } \\
\hline$<21$ & $45.28(523)$ & $58.94(234)$ & $45.45(80)$ & $32.45(123)$ & $42.36(86)$ & $<0.001$ \\
\hline$\geq 21$ & $54.72(632)$ & $41.06(163)$ & $54.55(96)$ & $67.55(256)$ & $57.64(117)$ & \\
\hline \multicolumn{7}{|l|}{ Sex } \\
\hline Female & $49.61(573)$ & $61.21(243)$ & $48.86(86)$ & $44.33(168)$ & $37.44(76)$ & $<0.001$ \\
\hline Male & $50.39(582)$ & $38.79(154)$ & $51.14(90)$ & $55.67(211)$ & $62.56(127)$ & \\
\hline \multicolumn{7}{|l|}{ Education level } \\
\hline Bachelor's degree & $79.05(913)$ & $84.13(334)$ & $73.86(130)$ & $73.88(280)$ & $83.25(169)$ & 0.001 \\
\hline Higher degree & $20.95(242)$ & $15.87(63)$ & $26.14(46)$ & 26.12 (99) & $16.75(34)$ & \\
\hline \multicolumn{7}{|l|}{ Past-year tobacco use } \\
\hline No & $36.10(417)$ & $57.79(241)$ & $16.79(70)$ & $18.71(78)$ & $6.71(28)$ & $<0.001$ \\
\hline Yes & $63.90(738)$ & $21.14(156)$ & $14.36(106)$ & $40.79(301)$ & $23.71(175)$ & \\
\hline \multicolumn{7}{|c|}{ Perceived friend approval } \\
\hline Disapprove & $28.40(328)$ & $52.90(210)$ & $31.82(56)$ & $6.33(24)$ & $18.72(38)$ & $<0.001$ \\
\hline Somewhat approve & $48.48(560)$ & $43.8(251)$ & $39.29(156)$ & $53.98(95)$ & $28.57(58)$ & \\
\hline Strongly approve & $14.03(162)$ & $3.39(13)$ & $5.99(23)$ & $64.91(246)$ & $50.25(102)$ & \\
\hline Don't know & $2.68(31)$ & $4.53(18)$ & $1.14(2)$ & $1.58(6)$ & $2.46(5)$ & \\
\hline \multicolumn{7}{|c|}{ Exposure to drunk driving messages } \\
\hline No & $24.33(281)$ & $15.37(61)$ & $23.30(41)$ & $32.98(125)$ & $26.60(54)$ & $<0.001$ \\
\hline Yes & $64.59(746)$ & $70.03(278)$ & $62.50(110)$ & $58.05(220)$ & $67.98(138)$ & \\
\hline Don't remember & $11.08(128)$ & $45 \cdot 31(58)$ & $19.53(25)$ & $26.56(34)$ & 8.59 (11) & \\
\hline
\end{tabular}

Percentages have been rounded to 1 decimal place and may not total 100.

$A U D=$ alcohol use disorder; $P Y=$ past-year . 


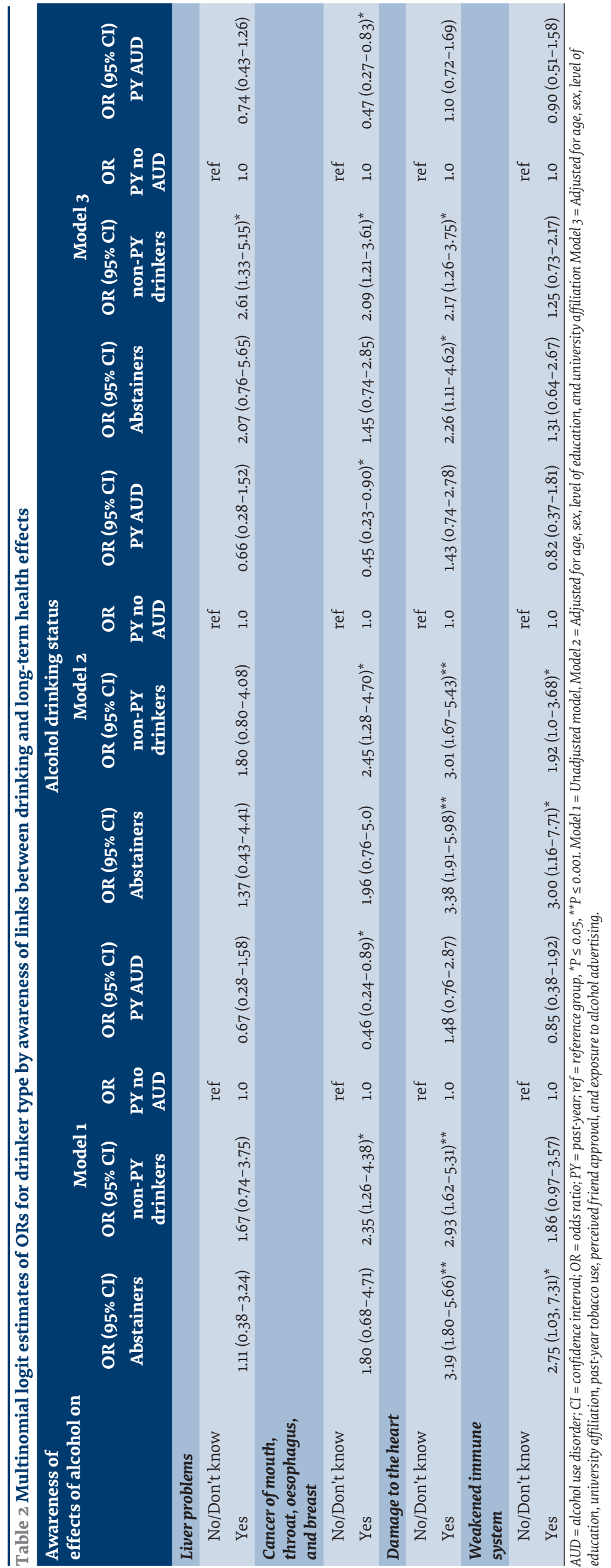

\section{Results}

\section{Sample description}

Out of the total 1155 students, 397 (34.4\%) were abstainers (never tried alcohol), 176 (15.2\%) were non-past-year drinkers (tried alcohol but did not drink in the past year), 379 (32.8\%) were past-year drinkers with no AUD (drank in the past year but did not meet DSM-5 criteria for AUD), and 203 (17.6\%) were past-year drinkers with a DSM-5defined AUD (Table 1). Among past-year drinkers with AUDs, data further revealed that they were distributed as follows: 118 (58.1\%) with mild AUD, $42(20.7 \%)$ with moderate AUD and $43(21.2 \%)$ with severe AUD.

Sample demographic characteristics are described in Table 1. Of the 1155 students, 582 (50.4\%) were male and $632(54.7 \%)$ were aged $\geq$ 21 years (range 18-25, standard deviation $=1.84$ ). Most participants were pursuing a Bachelor's degree $(\mathrm{I}=913 ; 79.1 \%)$ and most smoked tobacco in the past year (cigarettes or waterpipe) $(\mathrm{I}=738$; $63.9 \%$ ). Most students were aware that drinking too much causes problems in the liver (fatty liver, alcoholic hepatitis, or cirrhosis) ( $n=947 ; 82.0 \%$; data not shown). Fewer students were aware that alcohol consumption can cause damage to the heart, resulting in irregular heartbeat, stroke or hypertension ( $\mathrm{n}=888$; 76.8\%; data not shown), or weaken the immune system $(n=802 ; 69.4 \%$; data not shown), or cause cancers of the mouth, throat, oesophagus and breast $(n=715 ; 61.9 \%$; data not shown).

Table 1 also summarizes the bivariate association between alcohol consumption (i.e., drinker types) and demographic data described in the above paragraph, and all the associations were significant. Past-year drinkers with DSM-5 AUDs were more likely to be aged $\geq 21$ years, male, completing a BA (vs higher degree), past-year tobacco users, have peers who strongly approved of their drinking, and reported exposure to drinkdriving messages.

\section{Association between awareness of long-term alcohol effects and alcohol consumption: multinomial logit regression models}

Table 2 presents the unadjusted results (Model 1), adjusted results controlling for age, sex and university affiliation (Model 2), and adjusted results controlling for all the sociodemographic characteristics presented in Table 1 in addition to university affiliation. Abstainers, non-past-year drinkers, and past-year drinkers with an AUD were compared with the reference group of pastyear drinkers without an AUD. Only results of 
Model 3 are presented are interpreted since the 3 models generated similar findings.

Awareness of each of the 4 long-term alcohol effects varied in their association with the outcome of AUD (Table 2). Non-past-year ever drinkers were 2.6 times more likely to know that alcohol consumption was a risk factor for liver problems. Compared with past-year drinkers with no AUD, non-past-year ever drinkers were twice as likely to know about the link between alcohol and cancer of the mouth, throat, oesophagus and breast, while past-year drinkers with an AUD were about 53\% less likely to know about this link. Additionally, abstainers and non-past-year ever drinkers were about twice more likely to know that alcohol can cause damage to the heart, as compared with past-year drinkers with no AUD. Awareness of the links between alcohol consumption and weakening of the immune system was not significantly associated with the outcome of alcohol consumption.

\section{Discussion}

In the present study, more than a quarter of the sample were unaware of some link between alcohol consumption and long-term health effects. Our results show that increased awareness of long-term alcohol effects was associated with a decreased likelihood of having AUDs, and that this is dependent on the type of long-term health consequence of which one is aware.

Contrary to a previous study that reported no association between knowledge of the effects of alcohol and actual consumption (7), we found an association between knowledge of alcohol-attributable cancer and drinker type - in some cases linked to diagnosable AUD. We found that non-past-year ever drinkers were more likely to know that alcohol could cause cancer of the mouth, throat, oesophagus and breast. Yet, pastyear drinkers with a diagnosable AUD, compared with those without an AUD, were less likely to know about the association of alcohol with these cancers. In terms of the link between alcohol and damage to the heart, students who were abstainers or non-past-year ever drinkers were more likely to know about this long-term health effect than were past-year drinkers without an AUD. No associations were observed for drinker type and awareness of alcohol as causing weakening of the immune system. These results were significant even after controlling for a number of potential confounders including age, sex, level of education, past-year tobacco use, perceived friend approval, and exposure to alcohol advertising. Altogether, our results were in the predicted direction, confirming that increasing awareness of specific types of long-term alcohol effects may decrease harmful alcohol use in young adults.

Our approach adds several aspects to previous studies. First, we used multiple measures to capture awareness of long-term effects associated with alcohol consumption, which was not considered in previous studies $(6,14,30)$. Second, we examined the effects of this measure on a clinically useful variable of alcohol abuse, past-year
DSM-5-defined AUDs (20). Previous studies have either examined a link between knowledge and frequency of alcohol consumption (8) or knowledge and high- or low-risk drinking (7,11). Additionally, this research was conducted in a middle-income country, where literature on this topic is particularly lacking, and where relative morbidity and mortality risks associated with alcohol consumption are particularly high (31). The current study provides initial support for the potential effectiveness of awareness campaigns that focus on the links between alcohol and specific long-term health effects. For instance, our findings support the use of health warning labels on retailed beverages in an effort to control alcohol consumption (9). For such interventions to have a large impact on society they should be included as components of a comprehensive programme, including evidencebased alcohol control policies (32).

Our findings must be interpreted in light of a few study limitations. First, due to the cross-sectional nature of the data, we cannot assume temporal causality between awareness of long-term alcohol effects and alcohol drinking status. However, previous cross-sectional and longitudinal research has demonstrated a link between knowledge of alcohol effects on drinking patterns (11-13). Second, we relied on self-reported questionnaires for alcohol consumption outcomes, which may have biased the responses, but this method has generally been found to be valid in measuring alcohol consumption (33). Third, although the current study included multiple potential confounders in the analysis, there may be others that were not addressed and that could have affected the results, such as religiosity (34). Fourth, we measured the association of health awareness with alcohol consumption and acknowledge the theoretical and research literature that notes the limited evidence of a direct association between knowledge and behaviour $(13,35)$. However, given the understanding of the necessity of awareness, ahead of change in attitudes, as well as the contradictory results found in linking awareness of longterm alcohol effects to alcohol consumption in previous research, we sought to contribute to the literature in this area. Fifth, a limitation of the main exposure variable is that all items assessing awareness of long-term alcohol effects were in the negative, where the correct answer was that alcohol is a risk factor for all suggested health effects. To measure true awareness of long-term effects of alcohol, a more thorough design will be needed where questions about long-term health outcomes that have not been linked to alcohol consumption (e.g., skin disease) are included. Lastly, despite the heterogeneity of the sample consisting of various public and private universities, convenience sampling impedes the ability to generalize the results (mainly the proportions) to all Lebanese college students. Future studies should examine the potentially moderating role of sex, and the mediating role of risk perceptions when investigating the association between awareness of distinct types of long-term effects of alcohol and direct measures of alcohol consumption behaviour. 


\section{Conclusion}

Young adulthood is a significant opportunity to address harmful alcohol consumption, which is a largely preventable cause of cancer and other long-term health conditions. Our study conclusions have direct implications for harm-reduction strategies aimed at controlling alcohol consumption in this population. By increasing awareness of long-term effects of alcohol such as cancer of the mouth, throat, oesophagus and breast among young adults, interventions could mitigate alcohol-related harm in the short term and may prevent adverse health consequences in adulthood and later stages of life.

Funding: This study was funded by the International Development Research Centre (IDRC), Canada (grant number 107201-001).

Competing interests: None declared.

\section{La connaissance des effets à long terme de l'alcool sur la santé est-elle importante ? Données d'un échantillon d'université au Liban \\ Résumé}

Contexte : Les recherches établissant un lien entre la sensibilisation aux effets de l'alcool sur la santé et l'usage nocif de l'alcool sont limitées.

Objectifs : Étudier le lien entre la sensibilisation aux effets à long terme de l'alcool et les troubles liés à l'usage nocif de l'alcool.

Méthodes : Des étudiants universitaires âgés de 18 à 25 ans ( $\mathrm{n}=1155)$ ont répondu à une auto-enquête. Il a été demandé aux participants s'ils savaient que l'alcool pouvait provoquer les affections suivantes : 1) problèmes au niveau du foie ; 2) cancers de la bouche, de la gorge, de l'œsophage et du sein ; 3) lésions cardiaques ; et 4) affaiblissement du système immunitaire. Des analyses de régression multinomiale ont été menées pour évaluer l'association entre la connaissance des effets à long terme de l'alcool et le statut de consommation d'alcool, tels qu'ils sont définis dans la section sur les troubles liés à l'usage nocif de l'alcool du Manuel diagnostique et statistique des troubles mentaux, cinquième édition (DSM-5).

Résultats: Un tiers des répondants (32,8\%) étaient des consommateurs d'alcool au cours de l'année écoulée et $18 \%$ ont été dépistés positifs pour des troubles liés à l'usage nocif de l'alcool selon le Manuel susmentionné. Par rapport aux consommateurs de l'année précédente n'ayant pas de troubles liés à l'usage nocif de l'alcool, les nonconsommateurs de l'année précédente étaient deux fois plus susceptibles de connaître le lien entre l'alcool et les cancers de la bouche, de la gorge, de l'œsophage et du sein. Les consommateurs de l'année précédente souffrant de troubles liés à l'usage nocif de l'alcool étaient moins susceptibles de connaître cette association. Les nonconsommateurs susmentionnés (par rapport aux consommateurs de l'année précédente n'ayant pas de troubles liés à l'usage nocif de l'alcool) étaient également 2,6 fois plus susceptibles de connaître les risques hépatiques liés à l'alcool.

Conclusions: Il existe une forte relation inverse entre la connaissance des effets de l'alcool et l'usage nocif chez les jeunes, ce qui apporte un soutien préliminaire à la nature protectrice des connaissances sur le statut de la consommation d'alcool. Il pourrait être utile de sensibiliser davantage le public aux effets à long terme de l'alcool sur la santé pour éduire les méfaits de ce produit.

$$
\begin{aligned}
& \text { هل من المهم معرفة الآثار الصحية لتعاطي الكحول على المدى الطويل؟ البراهين من عينة جامعية في لبنان } \\
& \text { نيكول خولي، ليليان عدنان غندور، سيرين عنوتي، ريها عادل عفيفي، ريها نقاش، على شلق، ناصر ياسين، سيلفيا مارتينز }
\end{aligned}
$$

$$
\begin{aligned}
& \text { الخلفية: لا يوجد كثير من البحوث التي تربط بين الوعي بالآثار الصحية لتعاطي الكحول وحالة تعاطي الكحول على نحو ضار. } \\
& \text { الأهداف: هدفت هذه الدراسة إلى تحري العلاقة بين الوعي بالآثار الصحية لتعاطي الكحول على المدى الطويل واضطر ابات تعاطي الكحول. }
\end{aligned}
$$

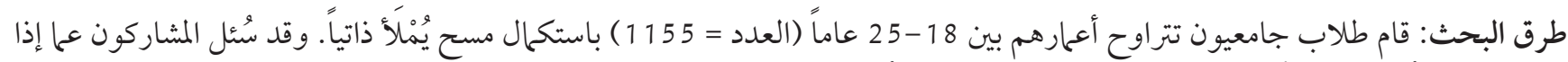

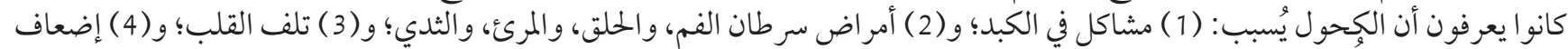

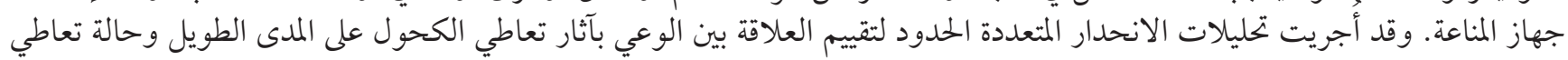

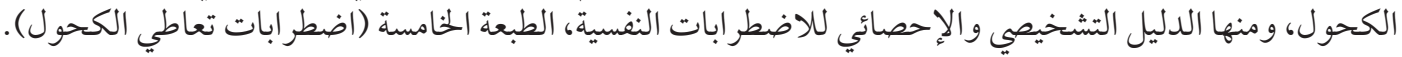

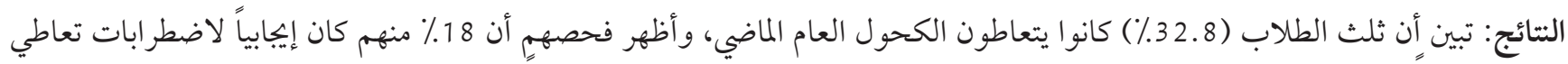

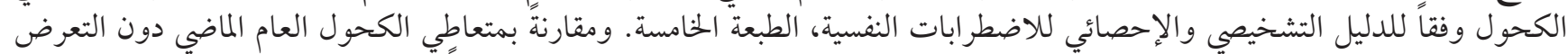

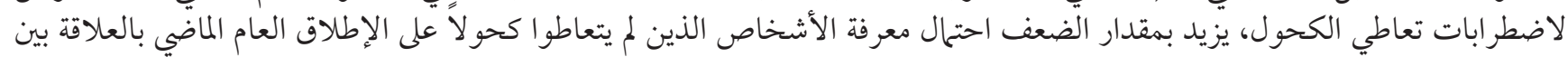




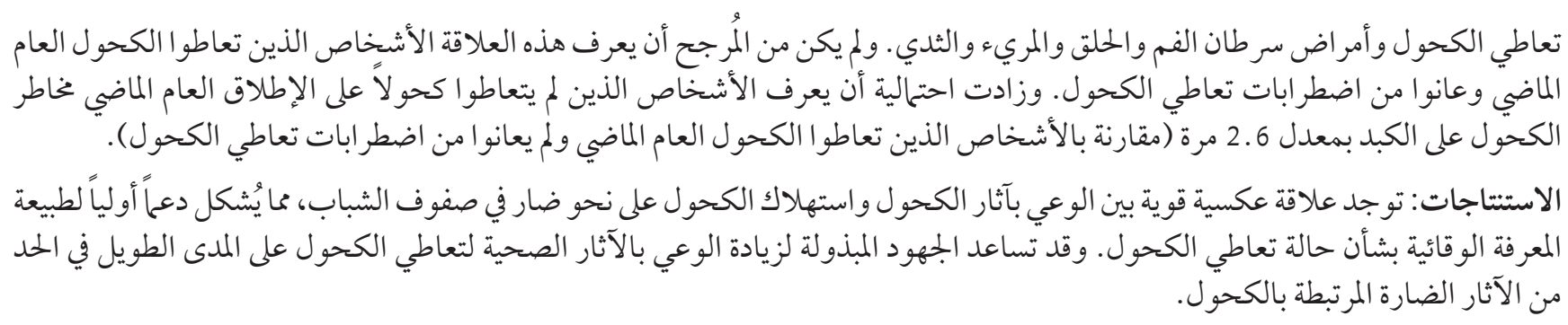

\section{References}

1. Griswold MG, Fullman N, Hawley C, Arian N, Zimsen SRM, Tymeson HD, et al. Alcohol use and burden for 195 countries and territories, 1990-2016: a systematic analysis for the Global Burden of Disease Study 2016. Lancet. 2018 Sep 22;392(10152):1015-35. https://doi.org/10.1016/So140-6736(18)31310-2

2. Chambers RA, Taylor JR, Potenza MN. Developmental neurocircuitry of motivation in adolescence: a critical period of addiction vulnerability. Am J Psychiatry. 2003 Jun;16o(6):1041-52. http://dx.doi.org/10.1176/appi.ajp.160.6.1041 PMID:12777258

3. McCambridge J, McAlaney J, Rowe R. Adult consequences of late adolescent alcohol consumption: a systematic review of cohort studies. PLoS Med. 2011 Feb 8;8(2):e1000413. http://dx.doi.org/10.1371/journal.pmed.1000413 PMID:21346802

4. Grant BF, Goldstein RB, Saha TD, Chou SP, Jung J, Zhang H, et al. Epidemiology of DSM-5 Alcohol Use Disorder: Results From the National Epidemiologic Survey on Alcohol and Related Conditions III. JAMA Psychiatry. 2015 Aug;72(8):757-66. http://dx.doi. org/10.1001/jamapsychiatry.2015.0584 PMID:26039070

5. Roerecke M, Rehm J. Cause-specific mortality risk in alcohol use disorder treatment patients: a systematic review and meta-analysis. Int J Epidemiol. 2014 Jun;43(3):906-19. http://dx.doi.org/10.1093/ije/dyuo18 PMID:24513684

6. Buykx P, Gilligan C, Ward B, Kippen R, Chapman K. Public support for alcohol policies associated with knowledge of cancer risk. Int J Drug Policy. 2015 Apr;26(4):371-9. http://dx.doi.org/10.1016/j.drugpo.2014.08.006 PMID:25217801

7. Buykx P, Li J, Gavens L, Hooper L, Loyatt M, de Matos EG, et al. Public awareness of the link between alcohol and cancer in England in 2015: a population-based survey. BMC Public Health. 2016 Nov 30;16(1194):1-12. http://dx.doi.org/10.1186/s12889-0163855-6 PMID:27899099

8. Lagerlund M, Hvidberg L, Hajdarevic S, Fischer Pedersen A, Runesdotter S, Vedsted P, et al. Awareness of risk factors for cancer: a comparative study of Sweden and Denmark. BMC Public Health. 2015 Nov 23;15:1156. http://dx.doi.org/10.1186/s12889-015-25129 PMID:26596679

9. Coomber K, Mayshak R, Curtis A, Miller PG. Awareness and correlates of short-term and long-term consequences of alcohol use among Australian drinkers. Aust N Z J Public Health. 2017 Jun;41(3):237-42. http://dx.doi.org/10.1111/1753-6405.12634 PMID:28110495

10. Annual alcohol poll 2017: attitudes and behaviours [website]. Deakin, ACT: FARE; 2017 (http://fare.org.au/annual-alcohol-poll-2017-attitudes-and-behaviours/, accessed 19 August 2020).

11. Kippen R, James E, Ward B, Buykx P, Shamsullah A, Watson W, et al. Identification of cancer risk and associated behaviour: implications for social marketing campaigns for cancer prevention. BMC Cancer. 2017 Aug 17;17(1):550. http://dx.doi.org/10.1186/ S12885-017-3540-x PMID:28818048

12. Grevenstein D, Nagy E, Kroeninger-Jungaberle H. Development of risk perception and substance use of tobacco, alcohol and cannabis among adolescents and emerging adults: evidence of directional influences. Subst Use Misuse. 2015 Feb;50(3):376-86. http://dx.doi.org/10.3109/10826084.2014.984847 PMID:25496046

13. Scheier LM, Botvin GJ. Expectancies as mediators of the effects of social influences and alcohol knowledge on adolescent alcohol use: a prospective analysis. Psychol Addictive Behav. 1997;11(1):48-64. https://doi.org/10.1037/0893-164X.11.1.48

14. Martin N, Buykx P, Shevills C, Sullivan C, Clark L, Newbury-Birch D. Population level effects of a mass media alcohol and breast cancer campaign: a cross-sectional pre-intervention and post-intervention evaluation. Alcohol Alcohol. 2018 Jan 1;53(1):31-8. http://dx.doi.org/10.1093/alcalc/agx071 PMID:29155922

15. Ghandour L, Chalak A, El-Aily A, Yassin N, Nakkash R, Tauk M, et al. Alcohol consumption in the Arab region: what do we know, why does it matter, and what are the policy implications for youth harm reduction? Int J Drug Policy. 2016 Feb;28:10-33. http:// dx.doi.org/10.1016/j.drugpo.2015.09.013 PMID:26547300

16. Ghandour L, Afifi R, Fares S, El Salibi N, Rady A. Time trends and policy gaps: the case of alcohol misuse among adolescents in Lebanon. Subst Use Misuse. 2015;50(14):1826-39. http://dx.doi.org/10.3109/10826084.2015.1073320 PMID:26646475

17. Nakkash R, Ghandour LA, Anouti S, Nicolas J, Chalak A, Yassin N, et al. Surveying Alcohol Outlet Density in Four Neighborhoods of Beirut Lebanon: Implications for Future Research and National Policy. Int J Environ Res Public Health. 2018 Sep 14;15(9):2006. http://dx.doi.org/10.3390/ijerph15092006 PMID:30223460

18. Karam EG, Maalouf WE, Ghandour LA. Alcohol use among university students in Lebanon: prevalence, trends and covariates: the IDRAC University Substance Use Monitoring Study (1991 and 1999). Drug Alcohol Dependence. 2004 Dec 7;76(3):273-86. https://doi.org/10.1016/j.drugalcdep.2004.06.003 
19. Yassin N, Afifi R, Singh N, Saad R, Ghandour L. "There is zero regulation on the selling of alcohol": the voice of the youth on the context and determinants of alcohol drinking in Lebanon. Qual Health Res. 2018 Apr;28(5):733-44. http://dx.doi. org/10.1177/1049732317750563 PMID:29307267

20. American Psychiatric Association. Diagnostic and statistical manual of mental disorders, fifth ed. Arlington, VA: American Psychiatric Publishing; 2013.

21. Miller NS, Gold MS. Comorbid cigarette and alcohol addiction: epidemiology and treatment. J Addict Dis. 1998;17(1):55-66. http:// dx.doi.org/10.1300/J069v17no1_06 PMID:9549603

22. Myers MG, Kelly JF. Cigarette smoking among adolescents with alcohol and other drug use problems. Alcohol Res Health. 2006;29(3):221-7. PMID:17373413

23. Grucza RA, Bierut LJ. Cigarette smoking and the risk for alcohol use disorders among adolescent drinkers. Alcohol Clin Exp Res. 2006 Dec;30(12):2046-54. http://dx.doi.org/10.1111/j.1530-0277.2006.00255.x PMID:17117970

24. Maziak W. The waterpipe: an emerging global risk for cancer. Cancer Epidemiol. 2013 Feb;37(1):1-4. http://dx.doi.org/10.1016/j. canep.2012.10.013 PMID:23196170

25. Akl EA, Gunukula SK, Aleem S, Obeid R, Jaoude PA, Honeine R, et al. The prevalence of waterpipe tobacco smoking among the general and specific populations: a systematic review. BMC Public Health. 2011 Apr 19;11:244. http://dx.doi.org/10.1186/1471-2458 11-244 PMID:21504559

26. Akl EA, Ward KD, Bteddini D, Khaliel R, Alexander AC, Lotfi T, et al. The allure of the waterpipe: a narrative review of factors affecting the epidemic rise in waterpipe smoking among young persons globally. Tob Control. 2015;24(Suppl 1):i13-21. http://dx. doi.org/10.1136/tobaccocontrol-2014-051906

27. Merianos AL, Rosen BL, Montgomery L, Barry AE, Smith ML. Impact of perceived risk and friend influence on alcohol and marijuana use among students. J Sch Nurs. 2017 Dec;33(6):446-55. http://dx.doi.org/10.1177/1059840517717591 PMID:28675076

28. Deutsch AR, Chernyavskiy P, Steinley D, Slutske WS. Measuring peer socialization for adolescent substance use: a comparison of perceived and actual friends' substance use effects. J Stud Alcohol Drugs. 2015 Mar;76(2):267-77. http://dx.doi.org/10.15288/ jsad.2015.76.267 PMID:25785802

29. Rehm J, Gmel GE, Sr., Gmel G, Hasan OSM, Imtiaz S, Popova S, et al. The relationship between different dimensions of alcohol use and the burden of disease-an update. Addiction. 2017 Jun;112(6):968-1001. http://dx.doi.org/10.1111/add.13757 PMID:28220587

30. Bowden JA, Delfabbro P, Room R, Miller CL, Wilson C. Prevalence, perceptions and predictors of alcohol consumption and abstinence among South Australian school students: a cross-sectional analysis. BMC Public Health. 2017 Jun 7;17(1):549. http://dx.doi. org/10.1186/s12889-017-4475-5 PMID:28592268

31. Global status report on alcohol and health 2018. Geneva; World Health Organization; 2018 (https://www.who.int/substance_ abuse/publications/global_alcohol_report/en/, accessed 19 August 2020).

32. Wakefield MA, Loken B, Hornik RC. Use of mass media campaigns to change health behaviour. Lancet. 2010 Oct 9;376(9748):1261-71. http://dx.doi.org/10.1016/So140-6736(10)60809-4 PMID:20933263

33. Del Boca FK, Darkes J. The validity of self-reports of alcohol consumption: state of the science and challenges for research. Addiction. 2003 Dec;98(Suppl 2):1-12. http://dx.doi.org/10.1046/j.1359-6357.2003.00586.x PMID:14984237

34. Ghandour LA, Karam EG, Maalouf WE. Lifetime alcohol use, abuse and dependence among university students in Lebanon: exploring the role of religiosity in different religious faiths. Addiction. 2009 Jun;104(6):940-8. http://dx.doi.org/10.1111/j.13600443.2009.02575.x PMID:19466919

35. Wakefield MA, Brennan E, Dunstone K, Durkin SJ, Dixon HG, Pettigrew S, et al. Immediate effects on adult drinkers of exposure to alcohol harm reduction advertisements with and without drinking guideline messages: experimental study. Addiction. 2018 Jun;113(6):1019-29. http://dx.doi.org/10.1111/add.14147 PMID:29486097 